\title{
BMJ Open Systematic review of behavioural smoking cessation interventions for older smokers from deprived backgrounds
}

\author{
Pamela Smith (D) , ${ }^{1}$ Ria Poole, ${ }^{1}$ Mala Mann, ${ }^{2}$ Annmarie Nelson, ${ }^{3}$ Graham Moore, ${ }^{4}$ \\ Kate Brain ${ }^{1}$
}

To cite: Smith P, Poole R, Mann M, et al. Systematic review of behavioural smoking cessation interventions for older smokers from deprived backgrounds. BMJ Open 2019;9:e032727. doi:10.1136/ bmjopen-2019-032727

- Prepublication history for this paper is available online. To view these files, please visit the journal online (http://dx.doi.org/ 10.1136bmjopen-2019-032727)

Received 04 July 2019

Revised 02 October 2019

Accepted 07 October 2019

Check for updates

(C) Author(s) (or their employer(s)) 2019. Re-use permitted under CC BY-NC. No commercial re-use. See rights and permissions. Published by BMJ.

${ }^{1}$ Division of Population Medicine, Cardiff University, Cardiff, UK ${ }^{2}$ Specialist Unit for Review Evidence, Cardiff University, Cardiff, UK

${ }^{3}$ Marie Curie Research Centre, Cardiff University, Cardiff, UK

${ }^{4}$ School of Social Sciences, Cardiff University, Cardiff, UK

Correspondence to

Pamela Smith;

smithp18@cardiff.ac.uk

\section{ABSTRACT}

Introduction The associations between smoking prevalence, socioeconomic group and lung cancer outcomes are well established. There is currently limited evidence for how inequalities could be addressed through specific smoking cessation interventions (SCls) for a lung cancer screening eligible population. This systematic review aims to identify the behavioural elements of SCls used in older adults from low socioeconomic groups, and to examine their impact on smoking abstinence and psychosocial variables.

Method Systematic searches of Medline, EMBASE, PsychInfo and CINAHL up to November 2018 were conducted. Included studies examined the characteristics of SCls and their impact on relevant outcomes including smoking abstinence, quit motivation, nicotine dependence, perceived social influence and quit determination. Included studies were restricted to socioeconomically deprived older adults who are at (or approaching) eligibility for lung cancer screening. Narrative data synthesis was conducted. Results Eleven studies met the inclusion criteria. Methodological quality was variable, with most studies using self-reported smoking cessation and varying length of follow-up. There were limited data to identify the optimal form of behavioural SCI for the target population. Intense multimodal behavioural counselling that uses incentives and peer facilitators, delivered in a community setting and tailored to individual needs indicated a positive impact on smoking outcomes.

Conclusion Tailored, multimodal behavioural interventions embedded in local communities could potentially support cessation among older, deprived smokers. Further highquality research is needed to understand the effectiveness of SCls in the context of lung screening for the target population.

PROSPERO registration number CRD42018088956.

\section{INTRODUCTION}

Smoking is the leading global cause of death and disease ${ }^{1}$ and data show that there are approximately 7.4 million adult cigarette smokers in the $\mathrm{UK}^{2}{ }^{3}$. Twenty-six per cent of smokers in the UK are aged 50 years or older $^{3}$; these individuals tend to have long standing smoking histories, are often from

\section{Strengths and limitations of this study}

- There is a current gap in knowledge about the most suitable form of behavioural smoking cessation intervention (SCl) for older, deprived smokers who are most likely to be eligible for lung screening.

- This systematic review suggests that tailored, multimodal behavioural SCls could support smoking cessation for those most likely to be eligible for lung screening; however, the studies included in the review were heterogeneous in design, $\mathrm{SCl}$ modality, sample size, intervention timing and measurement of smoking abstinence.

- There is a lack of rigorous, high quality research for the target population.

deprived communities and are a population that are likely to be eligible for future lung screening implementation. The associations between smoking prevalence, socioeconomic group and a range of chronic disease outcomes, including lung cancer outcomes are well established, with higher smoking rates and greater lung cancer incidence and mortality ${ }^{4-6}$ among people living in deprived areas.

The US Preventive Services Task Force recommends annual low-dose computed tomography (LDCT) screening for those who are high-risk heavy smokers, including adults aged 55-80 years old, with a 30 pack-year history ${ }^{7}$. LDCT lung cancer screening has the potential to prompt a smoking cessation attempt and evidence for integrated smoking cessation support is growing ${ }^{8-11}$, with research demonstrating promising results for quit rates when using a combined approach of smoking cessation support in a lung screening setting ${ }^{9}$.

Prior to implementing an appropriate smoking cessation intervention (SCI) in a lung screening context in the UK, it is important to understand the factors that 
influence cessation attempts in older, deprived smokers who may be eligible for lung cancer screening. Known barriers to smoking cessation in this population include higher nicotine dependence, less motivation to quit, more life stress, lack of social support and differences in perceptions of smoking ${ }^{12-14}$. Smokers from a low socioeconomic background may find quitting more difficult due to lack of support from their family members or community with quit attempts ${ }^{15}$, partly due to higher smoking prevalence and normalisation of smoking in their social networks ${ }^{16}$. Studies suggest that cessation attempts in older smokers are more likely to fail due to heavy nicotine dependence and insufficient motivating factors such as self-efficacy to quit $^{1718}$

Using pharmacotherapy with structured behavioural support to assist smoking cessation has shown promise with disadvantaged smokers ${ }^{19}{ }^{20}$. Intensive SCIs involving tailored pharmacotherapy and behavioural counselling to increase self-efficacy are most effective for deprived smokers. ${ }^{21}$ However, further research is needed to understand specific characteristics of behavioural SCIs, such as mode of delivery, setting, intensity and duration, that could be used for older, deprived smokers.

A recent review by Iaccarino $e a^{22}$ attempted to identify the best approach for delivering SCIs in a lung cancer screening setting and concluded that the optimal strategy remains unclear. There is a need to identify gaps in the evidence surrounding the optimal models for integrated smoking cessation in a lung screening setting, focusing specifically on a disadvantaged lung screening eligible population, as well as gain a better understanding of what form of SCI may work best for this population in the UK.

The aims of this systematic review were to identify the behavioural aspects of SCIs for older, deprived adults who are eligible (or approaching eligibility) for lung cancer screening, and to explore which elements of the interventions were most effective in reducing smoking abstinence and modifying psychosocial variables. The findings from the systematic review will contribute to further understanding of optimal SCIs for individuals who are a target population for lung cancer screening.

\section{METHODS}

The systematic review was registered on PROSPERO and followed the Preferred Reporting Items for Systematic Reviews and Meta-Analyses (PRISMA) guidelines ${ }^{23}$. Throughout all stages of the search, data extraction and quality appraisal, $20 \%$ of studies were double-checked for consistency by another member of the team (RP). All discrepancies were resolved through discussion. Data duplication was managed by removing duplications using a reference management software package (EndNote X9), which were then manually checked.

\section{Search strategy}

The literature was searched from 1990 to November 2018 on electronic databases: Medline, EMBASE, PsychInfo and CINAHL. Search terms related to smoking cessation, SCIs and socioeconomic status were used (table 1). To limit restricting the search in relation to age, papers were manually screened to identify studies that used a relevant sample.

\section{Study eligibility criteria}

All searches were restricted to high-income countries ${ }^{24}$. Inclusion criteria for the included publications were; 'Socioeconomically deprived groups' that defined their sample through individual level indicators (eg, educational level, income) or area level indicators (eg, postcode). 'Older adults', defined as aged 50 years+ (or when the majority of the sample was aged 40+) were included to represent a sample at or approaching lung cancer screening age ${ }^{25}$. The review included studies that examined behavioural

\begin{tabular}{|c|c|c|}
\hline PICO & Description & Search terms and connectors \\
\hline Population & $\begin{array}{l}\text { Individuals from socioeconomically deprived } \\
\text { groups, defined through either individual or area } \\
\text { level indicators }\end{array}$ & $\begin{array}{l}\text { (Depriv }^{*} \text { or disadvantage* or inequit* or } \\
\text { socioeconomic or socio-economic or } \\
\text { sociodemographic or socio-demographic } \\
\text { or social class or deprivation group or } \\
\text { poverty or low income or social welfare).tw. }\end{array}$ \\
\hline Comparison & $\begin{array}{l}\text { All study types with a pre-intervention/post- } \\
\text { intervention and/or a control group }\end{array}$ & - \\
\hline
\end{tabular}


aspects of SCIs and outcomes including smoking abstinence and psychosocial variables such as quit motivation, nicotine dependence, perceived social influence and quit determination.

\section{Data extraction and synthesis}

Study outcomes, including moderating variables and selected study features were extracted. Where relevant, statistical associations between variables are described in order to examine relationships within and between the included studies. Data from qualitative elements of included studies were extracted and a narrative synthesis was conducted. Due to the heterogeneity of included studies, a narrative synthesis was performed using guidance outlined by Popay et $a l^{26}$ and organised under relevant behavioural intervention elements.

\section{Critical appraisal}

The methodological quality of included studies and risk of bias was assessed using an adapted Critical Appraisal Skills Programme (CASP) tool ${ }^{27}$. Quality was assessed according to each domain on the checklist including rationale, study design, recruitment, sample size, data collection and analysis, ethical issues, reporting of findings and contribution to research. The CASP tool was adapted to address quality of methods for verifying smoking abstinence, intervention type, and socioeconomic and age variation within the sample. Overall quality was categorised as high, medium or low.

\section{Patient and public involvement}

Patient and public involvement was not adopted for the review.

\section{RESULTS}

Eleven studies met the inclusion criteria (figure 1). Nine of the 11 studies were quantitative ${ }^{28-36}$ and two were mixedmethods design ${ }^{37}$. Three studies were randomised control trials, with the remaining using a range of nonrandomised designs. Two studies ${ }^{28} 34$ were conducted in a lung screening context. Quality of included studies was high $(n=2)$, medium $(n=5)$ and low $(n=4)$. Limitations of lower quality studies included measuring but not reporting a subgroup analysis of age and/or deprivation, study design, limited description of the intervention and statistically underpowered results. Where available, relevant statistical values are presented in table 2 .

Nine studies used a combination of nicotine replacement therapy and behavioural counselling ${ }^{28-30} 32-37$. One study used only nicotine replacement therapy ${ }^{31}$ and one used behavioural counselling without nicotine replacement therapy ${ }^{38}$. Results are presented in relation to

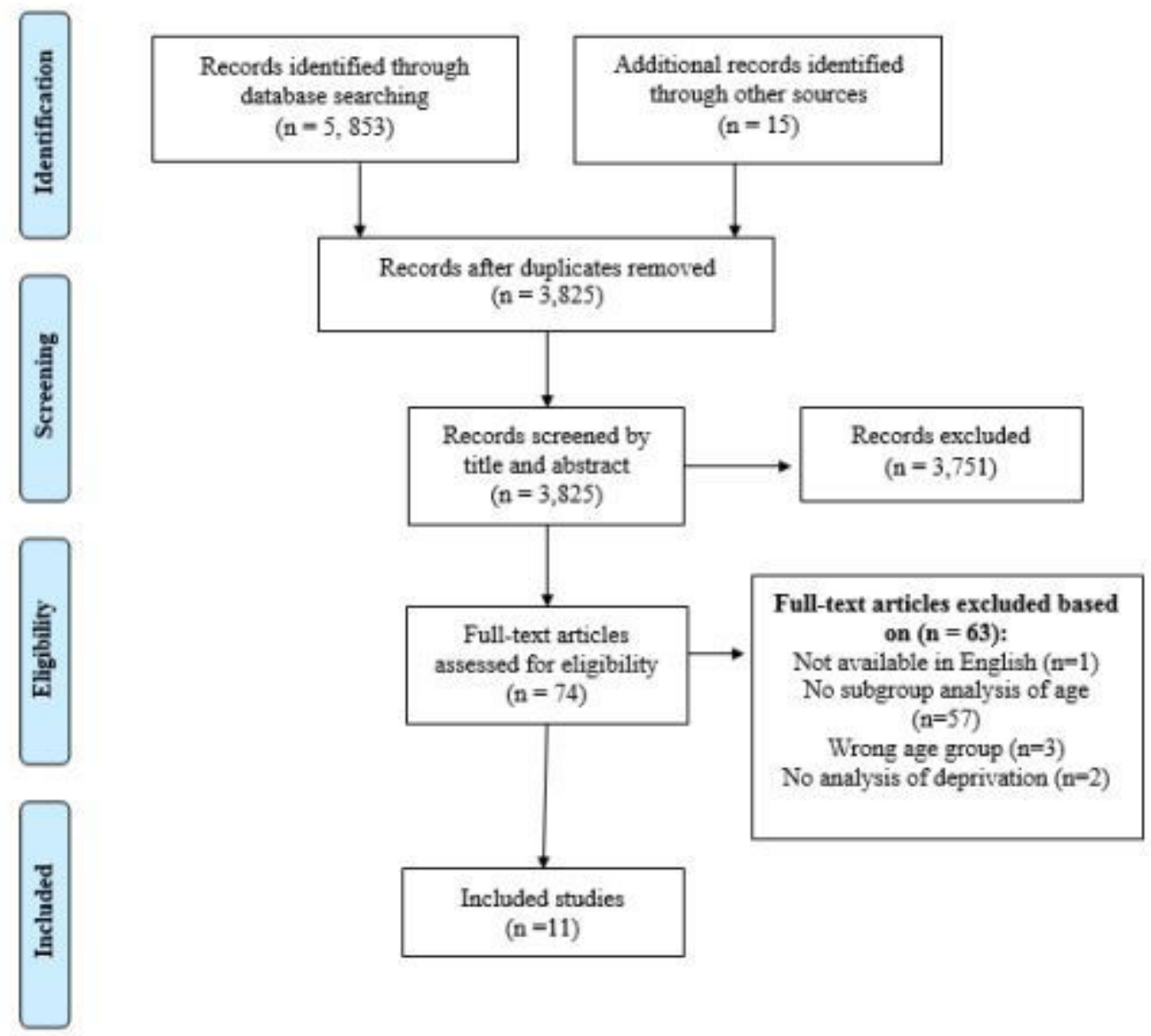

Figure 1 PRISMA flow diagram. 


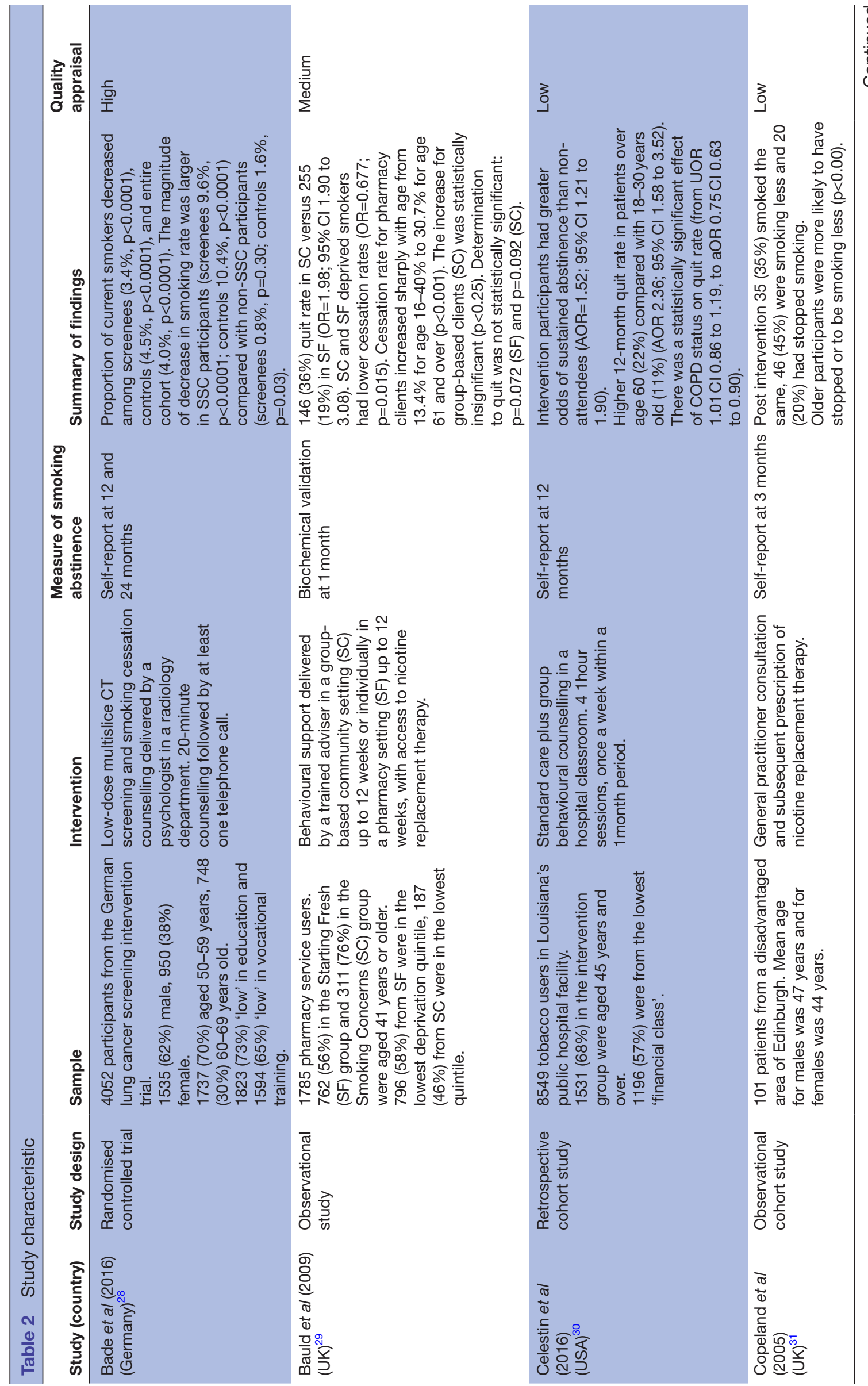




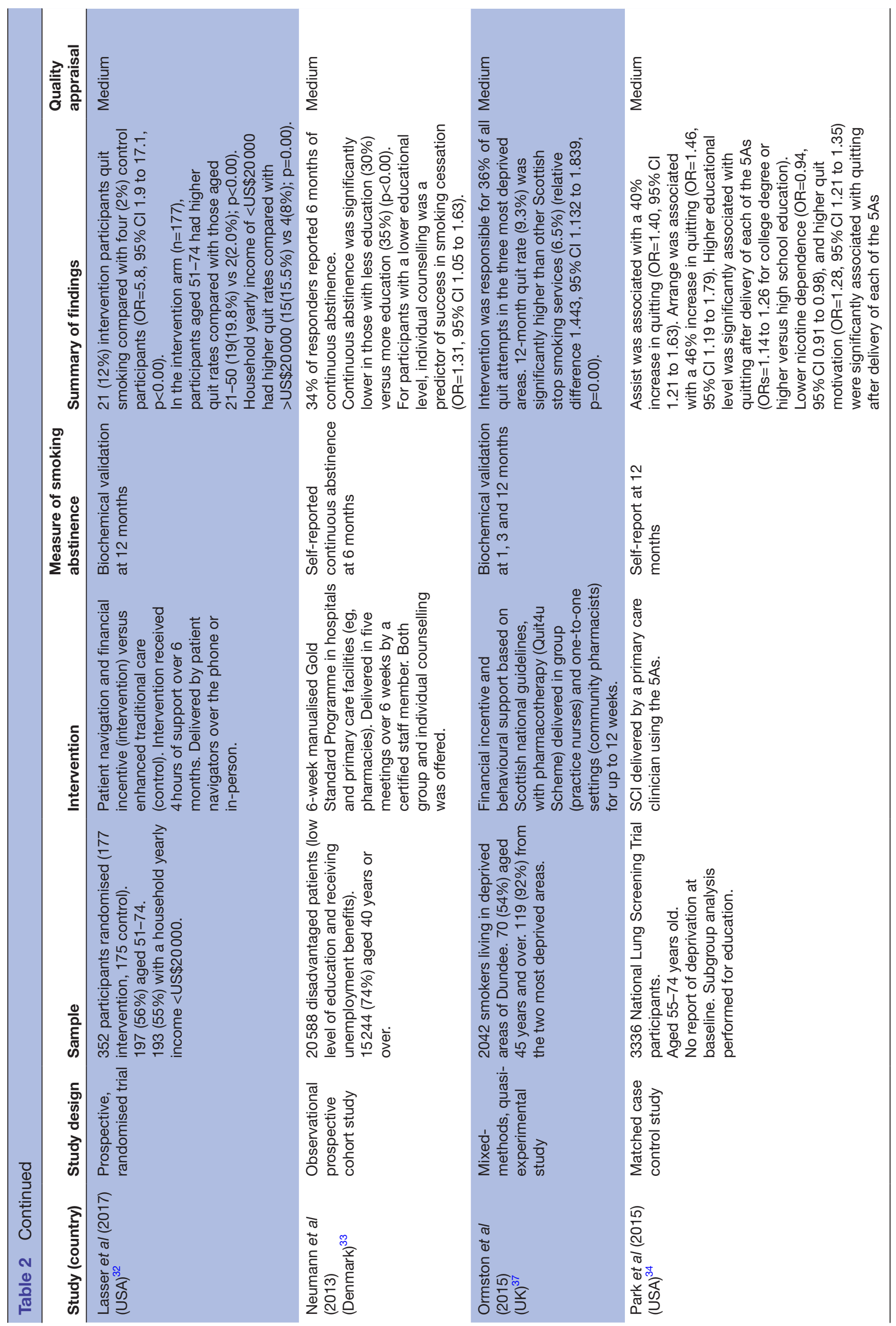




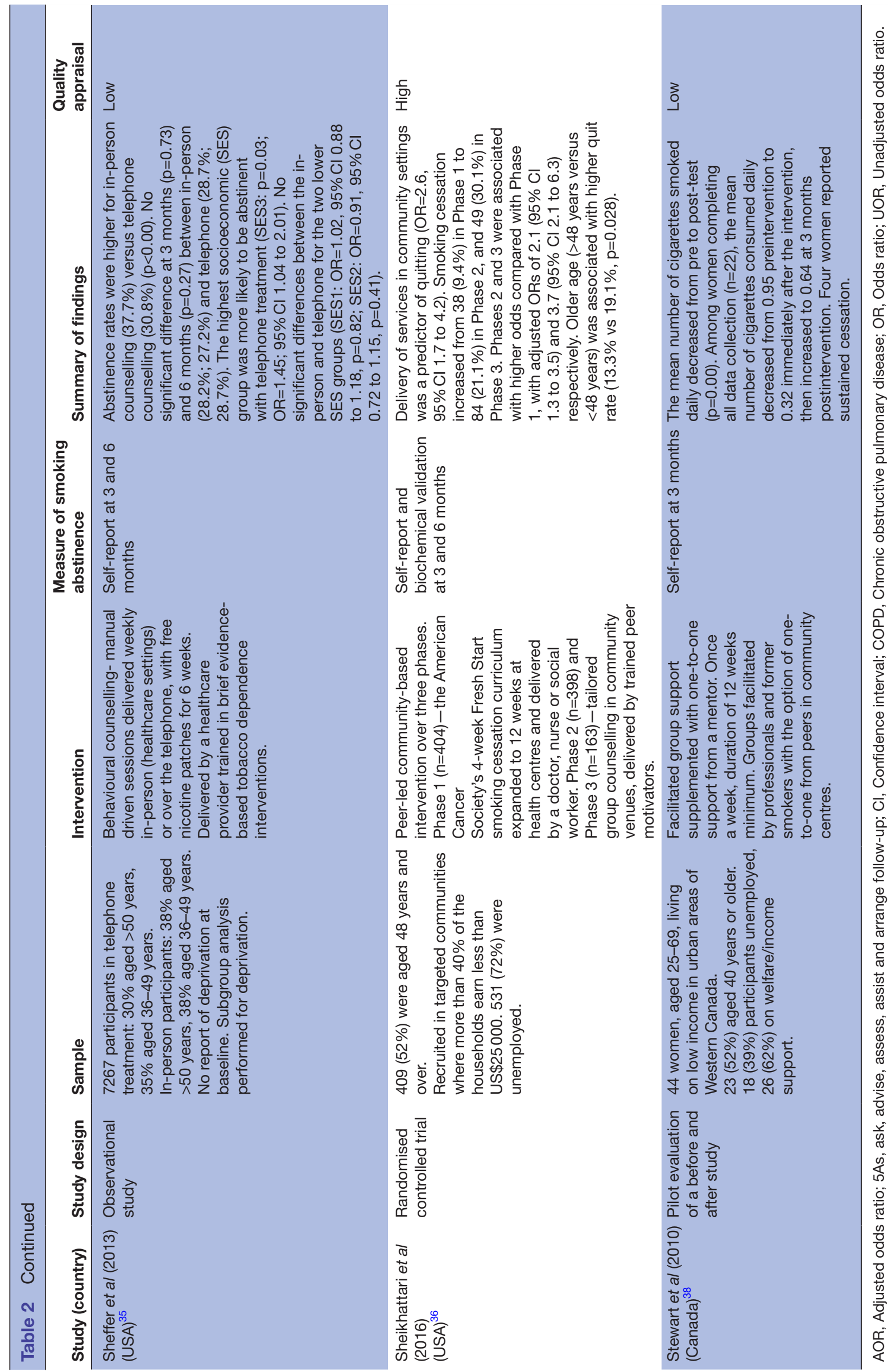


intervention elements including the behavioural content, setting, intervention provider and mode and duration of delivery. A subheading under each intervention element presents data on smoking outcomes. Further study characteristics and findings are also presented in table 2.

\section{Behavioural intervention content}

Ten studies focused on meeting the individual participant's needs using education and motivational techniques including support and encouragement ${ }^{28-30}$ 32-38. In all 10 studies, the interventions involved used motivational techniques with varying levels of intensity (table 2).

Nine studies used interventions that were of higher intensity ${ }^{28-30} 32$ 33 35-38. These studies involved incorporating specific action planning, tailored by the participant's level of quit motivation ${ }^{28}$, using a combination of manual-based teaching and patient education sessions including relapse prevention modules ${ }^{36}$, motivational interviewing techniques ${ }^{32}$, discussions on the benefits and costs of smoking versus cessation ${ }^{33}$, empowering strategies to enhance self-efficacy ${ }^{38}$ and cognitive behavioural content ${ }^{35}$.

Three studies used financial incentives as part of their intervention ${ }^{32} 3637$. A randomised control trial conducted by Lasser et al ${ }^{32}$ offered participants $\$ 750$ for abstinence at 12-month follow-up. This element of the intervention was combined with patient navigation in which trained navigators identified and discussed salient social contextual factors using motivational interviewing. Ormston $e t$ $a l^{37}$ combined behavioural support with financial incentives to participants on biochemically verified cessation.

\section{Outcomes}

A study by Park et $a l^{34}$ found that the 'assist' and 'arrange follow-up' elements of a brief SCI based on the 5As (ask, advise, assess, assist and arrange follow-up) alongside lung cancer screening significantly increased the odds of quitting. Results showed that the decrease in smoking rate was larger for participants who received behavioural support compared with those who did not. Smoking abstinence was higher in participants with a higher educational level (table 2).

Studies of interventions that involved using financial incentives found that older participants and those with the lowest income had higher quit rates (table 2). Ormston $e t a l^{37}$ found that quit rates for the intervention group were significantly higher compared with other stop smoking services (table 2). Seventy-one percent of participants reported that the incentive component was 'very' or 'quite useful' in helping them quit, with participants describing it as a 'bonus' or 'reward' to motivate them.

Stewart $e a^{38}$ reported qualitative data on self-efficacy for quitting and found that participants thought the education they gained from the intervention increased their awareness of their smoking habits, reasons why they smoked and the importance of quitting. Participants also reported an increase in the number of available support sources (eg, parents, spouse and friends) along with a significant increase in perceived social support ${ }^{38}$.

\section{Setting}

Two studies took place in a lung screening setting ${ }^{28} 34$ and used contrasting forms of interventions. Park et al ${ }^{34}$ offered a brief SCI delivered by a primary care clinician, whereas Bade et $a l^{28}$ used a more intensive intervention delivered by a psychologist who was trained in tobacco treatment. The latter study used a randomised control trial design with a large sample size and took place in the radiology department before or after the participant's screening.

Five studies were delivered in a variety of easily accessible community settings including community pharmacies $^{29} 3337$ and community venues such as centres and churches ${ }^{29} 36-38$ (table 2). Three studies took place at medical facilities such as local medical/health centres $^{313235}$ and two studies took place in hospitals ${ }^{30} 33$. One study delivered the intervention in both community and primary care settings ${ }^{33}$.

\section{Outcomes}

Stewart et al ${ }^{38}$ used a community-based intervention that took place in a local community centre, familiar to participants. Findings from this small-scale pilot study of female smokers suggested that the number of cigarettes smoked decreased post-intervention (table 2). Ormston et al ${ }^{37}$ compared intervention delivery in community pharmacies and behavioural support (both group and one-to one sessions) to other stop smoking services and demonstrated significantly higher quit rates in deprived communities (table 2).

Bauld et al ${ }^{29}$ showed that specialist-led group-based services have higher quit rates compared with oneto-one services that are provided by pharmacies. Cessation rates for pharmacy clients increased with age, and more deprived smokers had lower smoking cessation rates in both the pharmacy-led and one-to-one services (table 2). Sheikhattari et al ${ }^{36}$ found higher quit rates for community-based participants compared with those receiving support in clinics during phase 1 of the intervention (table 2). Results from this study also showed that older age (defined as over 48 years) was associated with higher quit rates for participants.

\section{Provider}

Interventions were delivered by a range of providers (table 2). Seven studies employed healthcare professionals such as general practitioners, primary care practice nurses, psychologists and pharmacists ${ }^{28} 303133-3538$. Two studies employed trained peer motivators to deliver their intervention. Sheikhattari et $a l^{36}$ used peer motivators who were former smokers to deliver the behavioural sessions. Peer motivators lived or worked in the community and were trained in delivering the intervention. Lasser $e^{a l}{ }^{32}$ used patient navigators who had completed 
10 hours of training in motivational interviewing techniques and had experience of working in community settings.

\section{Outcomes}

Smoking abstinence outcomes varied according to SCI provider (table 2). A small-scale observational study by Copeland $e a^{31}$ examined the use of nicotine replacement theory and a brief general practitioner consultation. Results showed that older smokers were more likely to have stopped smoking (table 2).

Sheikhattari et al ${ }^{36}$ demonstrated that subsequent phases of the intervention delivered by trained peer facilitators were associated with higher odds of quitting compared with the first phase where intervention delivery was conducted by a doctor, nurse or social worker (table 2). Findings from Lasser et $a l^{32}$ demonstrated that older participants and those with a lower household yearly income had higher quit rates (table 2).

Qualitative data from Stewart et $a l^{38}$ demonstrated that participants felt peer facilitators helped to support their cessation efforts as they were able to share personal experiences and strategies. Participants reported that they were able to learn coping strategies and techniques from other participants in the group which then helped them with their quit attempt.

\section{Mode and duration}

Studies varied in the mode and duration of delivery of SCIs (table 2). Seven studies examined both individual and group behavioural counselling sessions ${ }^{29} 303233353738$ (table 2) and four studies used only one-to-one behavioural support $^{28313234}$. Duration of interventions varied greatly between and within studies (table 2). The shortest duration was an intervention embedded in a general practitioner consultation $^{31}$ and the longest was 16 weeks of smoking cessation support ${ }^{38}$.

\section{Outcomes}

Bauld et al ${ }^{29}$ showed that participants accessing groupbased services were almost twice as likely as those who used individual pharmacy-based support to have quit smoking at 4 weeks (table 2). Similarly, Celestin et al ${ }^{30}$ showed that attendees of group behavioural counselling had significantly higher long-term quit rates compared with non-attendees. Sheikhattari et al ${ }^{36}$ used a six-week group-counselling module followed by a six-week relapse prevention module. Higher odds of quitting were associated with later phases of the intervention in which community-based group counselling was delivered (table 2).

Lasser et al ${ }^{32}$ delivered their one-to-one behavioural support over 6 months either in-person or over the telephone, with a goal of fourhours per participant. Results demonstrated that more participants from the intervention group had quit smoking in comparison to the control group (table 2). Bade et al ${ }^{28}$ also employed behavioural counselling in-person, with at least one subsequent telephone call for those who had specified a quit date. Participants were offered four telephone calls that lasted around 20 minutes in duration and findings demonstrated a larger decrease in smoking for screening attendees compared with non-attendees (table 2).

Sheffer $e a^{35}$ delivered both telephone and in-person behavioural counselling. Smoking abstinence rates were higher for in-person counselling, with smokers from higher socioeconomic groups more likely to quit after telephone counselling than smokers from lower socioeconomic groups. Neumann et $a l^{33}$ offered either group or individual counselling and demonstrated that for those with a lower educational level, individual counselling was a predictor of smoking cessation (table 2).

\section{Moderating variables}

Seven studies reported limited data on moderating variables ${ }^{28-30} 32$ 34-36. Bauld et al ${ }^{29}$ found that smokers who reported being 'extremely determined' to quit were more likely to be successful in their quit attempt. Celestin et $a l^{30}$ demonstrated that COPD status had a statistically significant effect on quit rates (table 2) and Park and colleagues $^{34}$ showed that lower nicotine dependence and higher quit motivation were significantly associated with quitting after the delivery of each of the 5As. Three RCTs demonstrated that participants who had a lower Fagerstrom score ${ }^{36}$, who were contemplating quitting $^{32}$ and reported high readiness to quit ${ }^{28}$ at baseline were more likely to have abstained from smoking post-intervention.

\section{DISCUSSION}

To our knowledge, this systematic review is the first to examine the influence of behavioural SCIs for an older, deprived population. The majority of included studies used a combination of pharmacotherapy and a form of behavioural counselling, supporting previous evidence that a combined approach is the most effective for older, deprived smokers ${ }^{21}$. Additionally, findings relating to the intensity, provider, mode, duration and setting of behavioural counselling are encouraging. Behavioural counselling delivered in a community setting and tailored to individual needs appeared to demonstrate a positive impact on smoking cessation outcomes.

Behavioural interventions identified in the current review used a range of approaches and although none of the included studies explicitly described their intervention as 'tailored', many used a form of behavioural counselling that was implicitly flexible according to the needs of the individuals. Interventions were implemented in locations that addressed barriers to access, such as local community centres, and intervention content was driven by the individual's psychological needs ${ }^{29}{ }^{36-38}$. Previous research suggests that in order for people to access stop smoking services, the appointments should be flexible and accessible ${ }^{39}$. 
The optimal mode and duration of intervention was unclear from our review, with findings suggesting varying success for both group and one-to-one behavioural support. The current results reflect similar findings from a review conducted in the UK. Bauld $e t$ al ${ }^{21}$ concluded that due to a dearth of studies examining subpopulations of smokers, further research is needed to determine the most effective models of treatment for smoking cessation and their efficacy with these subgroups ${ }^{21}$. The current review did, however, demonstrate that certain aspects of behavioural interventions, such as incentives, the use of peer facilitators and more intensive counselling are promising for encouraging cessation in older, deprived smokers. Additionally, limited data regarding the influence of moderating variables suggests that factors such as nicotine dependence, quit motivation and pre-existing health conditions such as COPD can impact the effectiveness of SCIs. Future research should aim to understand the needs and preferences of older, deprived smokers and focus on psychosocial mechanisms that can be targeted in more holistic level interventions.

The 11 studies included in the review were heterogeneous in design, SCI modality, sample size, intervention timing and measurement of smoking abstinence. Some of the included studies did not report CIs, thus making it difficult to interpret findings. Only three of the studies included were randomised control trials, of which one was underpowered ${ }^{32}$, thus the effectiveness results across the studies were modest. Chen and $\mathrm{Wu}^{40}$ also identified the need for controlled trials of SCIs for older smokers, in order to better understand the most suitable form of intervention for this population. Similarly, to findings from Piñeiro $e t a l$ s systematic review ${ }^{41}$, the studies in the current review did not consistently use biochemical verification of smoking cessation, with most relying on selfreported smoking cessation (table 2).

Various design aspects of the included studies, including the use of non-randomised methods, limited the extent to which firm conclusions can be drawn about the effectiveness of behavioural SCIs for older, deprived smokers. Only two studies included qualitative process evaluation data, limiting the ability to understand why specific intervention characteristics were more or less likely to influence smoking cessation outcomes. Evidence suggests that smokers from disadvantaged backgrounds face particular obstacles to successful quitting such as lack of support, higher nicotine dependence and life stress ${ }^{20}$. Further mixedmethods research is therefore warranted to understand why some forms of SCI support may be more suited to mitigating these barriers in the target population.

The findings indicate a clear lack of evidence from large-scale trials of effectiveness in a lung screening context as well as a lack of data reporting psychosocial moderators of cessation for older, deprived smokers. We acknowledge methodological limitations of the present systematic review. By restricting the inclusion criteria for age and socioeconomic group, several potentially relevant studies were excluded. For example, telephonebased counselling for smokers undergoing lung cancer screening, involving messages about risks of smoking in the context of lung scan results, can improve self-efficacy for quitting and the likelihood of a successful quit attempt ${ }^{42}$. However, our review highlights the current absence of robust evidence regarding behavioural SCIs that are effective for the lung screening eligible population of older, deprived smokers.

\section{CONCLUSION}

Our systematic review demonstrates the potential for tailored, multimodal SCIs for older, deprived smokers that can be embedded within disadvantaged communities. With the prospect of lung cancer screening being implemented in the UK and Europe in the near future, this research adds to the evidence base regarding promising SCIs for older, deprived populations who will benefit most from lung screening and integrated smoking cessation support. Further studies to understand the psychosocial barriers to quitting in the target population should be conducted to inform the design and conduct of high-quality trials of intervention effectiveness in older, deprived smokers.

Twitter Mala Mann @SysReviews and Annmarie Nelson @annmarie0

Acknowledgements The authors would like to thank Dr Grace McCutchan for her support and guidance throughout the review process.

Contributors PS, KB, MM, AN and GM were responsible for the concept, overall design and conduct of the review. MM gave additional support and advice on methodology including the search strategy. PS was responsible for collection of data and manuscript preparation. RP double checked $20 \%$ of included abstracts and full-texts. RP, MM, AN, GM and KB reviewed the edited manuscript preparation. All authors were involved in the interpretation of the results and approved the final version of the manuscript.

Funding This study was funded by School of Medicine, Cardiff University. RP is funded by a Cancer Research UK Population Research Committee Post-Doctoral Fellowship. AN's and MM's posts are supported by Marie Curie core grant funding (grant reference: MCCCFCO-11-C).

Competing interests None declared.

Patient consent for publication Not required.

Provenance and peer review Not commissioned; externally peer reviewed.

Data availability statement All data relevant to the study are included in the article or uploaded as supplementary information.

Open access This is an open access article distributed in accordance with the Creative Commons Attribution Non Commercial (CC BY-NC 4.0) license, which permits others to distribute, remix, adapt, build upon this work non-commercially, and license their derivative works on different terms, provided the original work is properly cited, appropriate credit is given, any changes made indicated, and the use is non-commercial. See: http://creativecommons.org/licenses/by-nc/4.0/.

ORCID iD

Pamela Smith http://orcid.org/0000-0002-0336-215X

\section{REFERENCES}

1 World Health Organisation. Report on the global tobacco epidemic, 2008. Available: www.who.int/tobacco/mpower/en/

2 Office for National Statistics. Adult smoking habits in the UK: 2017, 2018. Available: https://www.ons.gov.uk/peoplepopulationandc ommunity/healthandsocialcare/healthandlifeexpectancies/bulletins/ 
adultsmokinghabitsingreatbritain/2017 [Accessed cited 2019 February].

3 Office for National Statistics. Adult smoking habits in Great Britian 2017, 2017. Available: http://ash.org.uk/category/information-andresources/fact-sheets/

4 Information Services Division (ISD). Nhs national services Scotland, 2012. Available: http://www.isdscotland.org/Health-Topics/Cancer/ Publications/2012-04-24/2012-04-24-Cancer-Incidence-report.pdf? 49042910338

5 Welsh Cancer Intelligence and Surveillance Unit. Public health Wales 2015.

6 Shack L, Jordan C, Thomson CS, et al. Variation in incidence of breast, lung and cervical cancer and malignant melanoma of skin by socioeconomic group in England. BMC Cancer 2008;8:271.

7 Humphrey LL, Deffebach M, Pappas M, et al. Screening for lung cancer with low-dose computed tomography: a systematic review to update the U.S. preventive services Task force recommendation. Ann Intern Med 2013;159:411-20.

8 Ashraf $\mathrm{H}$, Tønnesen P, Holst Pedersen J, et al. Effect of CT screening on smoking habits at 1-year follow-up in the Danish lung cancer screening trial (DLCST). Thorax 2009;64:388-92.

9 Brain K, Carter B, Lifford KJ, et al. Impact of low-dose CT screening on smoking cessation among high-risk participants in the UK lung cancer screening trial. Thorax 2017;72:912-8.

10 Tammemägi MC, Berg CD, Riley TL, et al. Impact of lung cancer screening results on smoking cessation. J Natl Cancer Inst 2014;106.

11 van der Aalst CM, van den Bergh KAM, Willemsen MC, et al. Lung cancer screening and smoking abstinence: 2 year follow-up data from the Dutch-Belgian randomised controlled lung cancer screening trial. Thorax 2010;65:600-5.

12 Bryant J, Bonevski B, Paul C. A survey of smoking prevalence and interest in quitting among social and community service organisation clients in Australia: a unique opportunity for reaching the disadvantaged. BMC Public Health 2011;11:827.

13 Hiscock R, Judge K, Bauld L. Social inequalities in quitting smoking: what factors mediate the relationship between socioeconomic position and smoking cessation? J Public Health 2011;33:39-47.

14 Vangeli E, West R. Sociodemographic differences in triggers to quit smoking: findings from a national survey. Tob Control 2008;17:410-5.

15 Chandola T, Head J, Bartley M. Socio-Demographic predictors of quitting smoking: how important are household factors? Addiction 2004:99:770-7.

16 Mermelstein R, Cohen S, Lichtenstein E, et al. Social support and smoking cessation and maintenance. J Consult Clin Psychol 1986;54:447-53.

17 Benowitz NL. Nicotine addiction. N Engl J Med 2010;362:2295-303.

18 Fiore MC, Jaen CR, Baker TB, et al. Treating tobacco use and dependence: 2008 update U.S. public health service clinical practice guideline executive summary. Respir Care 2008;53:1217-22.

19 Bauld L, Judge K, Platt S. Assessing the impact of smoking cessation services on reducing health inequalities in England: observational study. Tob Control 2007;16:400-4.

20 Hiscock R, Bauld L, Amos A, et al. Socioeconomic status and smoking: a review. Ann N Y Acad Sci 2012;1248:107-23.

21 Bauld L, Bell K, McCullough L, et al. The effectiveness of NHS smoking cessation services: a systematic review. J Public Health 2010;32:71-82

22 laccarino JM, Duran C, Slatore CG, et al. Combining smoking cessation interventions with LDCT lung cancer screening: a systematic review. Prev Med 2019;121:24-32.

23 Moher D, Liberati A, Tetzlaff J, et al. Preferred reporting items for systematic reviews and meta-analyses: the PRISMA statement. $J$ Clin Epidemiol 2009;62:1006-12.
24 The World Bank [cited October 2018]. High income, 2018. Available: https://data.worldbank.org/income-level/high-income

25 Oudkerk M, Devaraj A, Vliegenthart R, et al. European position statement on lung cancer screening. Lancet Oncol 2017;18:e754-66.

26 Popay JR, HMSowden, Petticrew A. Guidance on the conduct of narrative synthesis in sytematic reviews: Institute for health research, 2006.

27 Singh J. Critical appraisal skills programme. CASP appraisal tools, 2013: 76 p

28 Bade M, Bahr V, Brandt U, et al. Effect of smoking cessation counseling within a randomised study on early detection of lung cancer in Germany, 2016: 959-68.

29 Bauld L, Chesterman J, Ferguson J, et al. A comparison of the effectiveness of group-based and pharmacy-led smoking cessation treatment in Glasgow, 2009: 308-162009 Feb.

30 Celestin MD, Tseng TS, Moody-Thomas S, et al. Effectiveness of group behavioral counseling on long-term quit rates in primary health care. Translational Cancer Research 2016;5:972-82.

31 Copeland L, Robertson R, Elton R. What happens when GPs proactively prescribe NRT patches in a disadvantaged community. Scott Med J 2005;50:64-8. 2005 May.

32 Lasser KE, Quintiliani LM, Truong V, et al. Effect of patient navigation and financial incentives on smoking cessation among primary care patients at an urban safety-net Hospital: a randomized clinical trial. JAMA Intern Med 2017;177:1798-807.

33 Neumann T, Rasmussen M, Ghith N, et al. The gold standard programme: smoking cessation interventions for disadvantaged smokers are effective in a real-life setting. Tob Control 2013;22:e9. 2013 Nov.

34 Park ER, Gareen IF, Japuntich S, et al. Primary care providerdelivered smoking cessation interventions and smoking cessation among participants in the National lung screening trial. JAMA Intern Med 2015;175:1509-16.

35 Sheffer C, Stitzer M, Landes R, et al. In-person and telephone treatment of tobacco dependence: a comparison of treatment outcomes and participant characteristics. Am J Public Health 2013;103:e74-82.

36 Sheikhattari P, Apata J, Kamangar F, et al. Examining smoking cessation in a community-based versus clinic-based intervention using community-based participatory research. $J$ Community Health 2016;41:1146-52. 2016 Dec.

37 Ormston R, van der Pol M, Ludbrook A. quit4u: the effectiveness of combining behavioural support pharmacotherapy and financial incentives to support smoking cessation, 2015: 121-33.

38 Stewart MJ, Kushner KE, Greaves L, et al. Impacts of a support intervention for low-income women who smoke. Soc Sci Med 2010;71:1901-9. 2010 Dec.

39 Venn A, Dickinson A, Murray R, et al. Effectiveness of a mobile, dropin stop smoking service in reaching and supporting disadvantaged UK smokers to quit. Tob Control 2016;25:33-8.

40 Chen D, Wu L-T. Smoking cessation interventions for adults aged 50 or older: a systematic review and meta-analysis. Drug Alcohol Depend 2015;154:14-24.

41 Piñeiro B, Simmons VN, Palmer AM, et al. Smoking cessation interventions within the context of low-dose computed tomography lung cancer screening: a systematic review. Lung Cancer 2016;98:91-8.

42 Zeliadt SB, Greene PA, Krebs P, et al. A proactive TelephoneDelivered risk communication intervention for smokers participating in lung cancer screening: a pilot feasibility trial. J Smok Cessat 2018;13:137-44. 